\title{
Preparation and properties of bioactive packaging materials on the starch base
}

\author{
Hana Smítková, Miroslav Marek, Jaroslav Dobiáš \\ Department of Food Preservation, Faculty of Food and Biochemical Technology, \\ Institute of Chemical Technology in Prague, Technická 5, 16628 Prague 6, Czech Republic \\ hana.smitkova@seznam.cz
}

\begin{abstract}
In this study the surface adjustment by two polymers with addition of preservatives of chosen packaging material on starch base with incorporated additives has been investigated. Its bioactive function was verified by measuring zones of inhibition and mutual comparison of bacteriocin released from samples coated with polymers. The best results were achieved when chosen sample containing $15 \%$ of sawdust, $5 \%$ of PVOH and $2 \%$ of calcium stearate was coated by $30 \%$ of Kombilak L1917 solution or $10 \%$ copolyamide $6 / 12$ solution. The addition of antimicrobial agents slightly increased hydrophilicity of coated samples. Immobilization of preservative had no significant effect on the mechanical strength of coated samples. For both types of relevant polymers used amount of immobilized Nisaplin was quite sufficient for effective inhibition of microbial cultures Lactobacillus Helveticus $\mathrm{CH} 1$.
\end{abstract}

Keywords: bioactive packaging, nisin, potato starch, surface adjustment

\section{Introduction}

Environment is in critical condition in these days. It is caused by the manufacturing, mining and agriculture. That is why the companies are very dedicated to environmental topics. These topics include the production of packaging from materials occurring in nature. Materials made from exhaustible fossil raw materials are being replaced with materials produced from raw materials obtained mainly from agricultural and food production.

Current research is largely concerned to use the starch (Shogren et al. 2002; Shogren et al. 1998; Cinelli et al. 2006). Previous research (Tiefenbacher 1993) has shown that a mixture of starch and water can be baked in an enclosed, heated form. Starch packaging materials are very fragile and are not resistant to humidity. From this reason they cannot be used in food industry. Properties of starch/ water packaging materials can be improved either by adding various additives, which are added into the structure of the packaging or by adjustment of the surface. Sawdust, waste paper pulp, organic and inorganic substances are mostly used as additive. Surface of the packaging materials can be adjusted by different types of polymers.

Polymers can contain other chemical substances which can maintain or improve packed product properties. If the packaging materials have these properties, they are called active packaging materials (Appendini et al. 2002). Active packaging materials are defined in Regulation 1935/2004 of the European Parliament and of the Council as "materials that are intended to extend the shelf-life or to maintain or improve the condition of packaged food. They are designed to deliberately incorporate components that would release or absorb substances into or from the packaged food or the environment surrounding the food" (1935/2004/EC).

Based on previous measurement (Smítková et al. 2012) sorption and mechanical properties of starch packaging with additions of calcium stearate, sawdust and polyvinylalcohol $(\mathrm{PVOH})$ in its internal structure, it was decided that the best properties were achieved in the case of the tray containing $15 \%$ of sawdust, $2 \%$ of calcium stearate and $5 \%$ of $\mathrm{PVOH}$. This packaging was chosen because of very good mechanical properties, in comparison with the basic type of starch/water packaging, and the addition of $5 \%$ of $\mathrm{PVOH}$ still prevent significant deterioration of sorption properties.

In this study, above mentioned packaging materials were adjusted by polymers - copolyamid 6/12 and Kombilak L1917 - with addition of preservative nisin (Marek et al. 2004). The effects of surface adjustment to strength, elongation to break and water resistance were determined. Bioactivity of prepared packaging material on starch base was verified by measuring of inhibition's zones measured by "plate" method.

\section{Materials and Methods}

\section{Materials}

In this research native potato starch, waste spruce sawdust from sawmill, calcium stearate p.a., poly- 
vinyl alcohol (® Mowiol, PVOH -12.3 $\pm 1.0 \%$ of acetyl units), Nisaplin (nisin preparation, activity $>1000 \mathrm{IU} / \mathrm{mg}$ ), copolyamide 6/12 from company Katechem Ltd Czech Republic, coating Kombilak L1917 supplied by company INVOS Svárov Czech Republic, ethyl methyl ketone, hydrochloric acid $36 \%$, sodium chloride, MRS agar were used.

In this research microorganism Lactobacillus Helveticus $\mathrm{CH} 1$ cultivated in ICT were used.

For mechanical testing machine Instron, Model 5544 from Instron Ltd. company were used together with Merlin computer program.

\section{Methods}

\section{The preparation of batter}

Potato native starch $(30 \mathrm{~g})$ and water $(45 \mathrm{~g})$ were mixed in a kitchen aid mixer in order to produce a homogenous basic mixture. For preparation of packaging materials $2 \% \mathrm{w} / \mathrm{w}$ of calcium stearate, $5 \% \mathrm{w} / \mathrm{w}$ of polyvinyl alcohol and $15 \% \mathrm{w} / \mathrm{w}$ of sawdust were added and mixed with starch/water batter. In order to produce compact trays, ratio of starch to water mixtures was $2: 3$.

\section{Baking process}

The starch foam trays with additives were prepared using a laboratory model-baking machine (ICT, Prague, Czech Republic). The top mould met the bottom mould during baking. Baking temperature of the top and bottom moulds was set at $200{ }^{\circ} \mathrm{C}$. The starch batter was inserted between the opened heated moulds. The moulds were closed and the batter baked into trays. Enough batter was drawn up into the syringe and dispensed into the mould so that after foaming, the starch just filled the mould and formed a complete tray of $8 \times 4 \mathrm{~cm}$. After baking, the samples of trays were adjusted to the size of $2.5 \times 5 \mathrm{~cm}$ or $3 \times 5 \mathrm{~cm}$.

\section{Surface adjustment}

The top surface of the prepared packaging material was coated with 5 or $10 \%$ of copolyamide $6 / 12$ solution dissolved in hot ethanol. Samples were placed in an oven heated to $130{ }^{\circ} \mathrm{C}$. After ethanol evaporation and cooling the second side of sample was coating with solution, too. Coated trays were kept in a dessicator.

Nisin, in the form of Nisaplin preparation, was applied in amount of $5 \% \mathrm{w} / \mathrm{w}$ to ethanol solution of $10 \%$ copolyamide. Ethanol for copolyamide and nisin dissolution was acidified with $0.02 \mathrm{M}$ hydrochloric acid. Coated samples were dried at $130{ }^{\circ} \mathrm{C}$ for $3-4$ minutes. After evaporation of the solvent cooled samples were placed in a dessicator and stored in the refrigerator.
The top surfaces of the trays were coated with a small amount of Kombilak L1917 with concentration of $15,20,25$ or $30 \%$. The solvent for this type of polymer was ethyl methyl ketone. Samples were dried at $90{ }^{\circ} \mathrm{C}$ for $4-5$ minutes. After evaporation of the solvent cooled samples were placed in a dessicator.

Nisin, in the form of Nisaplin preparation, were applied in amount of $5 \% \mathrm{w} / \mathrm{w}$ to $10 \mathrm{~g}$ of $30 \%$ Kombilak dissolved in ethyl methyl ketone. Coated samples were dried at $90^{\circ} \mathrm{C}$ for 3-4 minutes. After evaporation of the solvent cooled samples were placed in a dessicator and stored in the refrigerator.

\section{Determination of water sorption in direct contact}

The samples of starch packaging material of size $3 \times 5 \mathrm{~cm}$ were sealed with silicone adhesive plastic roller with inner diameter of $2.7 \mathrm{~cm}$. The sample was weighed. Cylinder was filled with $4 \mathrm{ml}$ of water at $(23 \pm 2)^{\circ} \mathrm{C}$. After 1 hour the excess water was poured, its remnants on the sample were removed and the sample was again weighed. The difference between the measured mass was calculated by weight of sorpted water into the sample and recalculated to the weight of the water sorpted by $1 \mathrm{dm}^{2}$.

\section{Determination of vapour sorption}

Dessicator with water was equilibrated at ambient temperature for 24 hours. After that $95 \%$ relative humidity $(\mathrm{RH})$ was established inside. Samples were taken into the dessicator and the amount of sorpted water was measured after 1, 3, 5 and 24 hours by trays weighting. Sorpted water vapour was calculated in the percentage (\%), respectively in the gram per square area $\left(\mathrm{g} \cdot \mathrm{dm}^{-2}\right)$.

\section{Mechanical testing}

After baking, packaging materials were adjusted to the size of $2.5 \times 5 \mathrm{~cm}$. Mechanical properties of the adjusted samples were measured with an Instron model 5544. The testing samples were placed to the machine supports and there the plunger beard down on the trays with $30 \mathrm{~mm} . \mathrm{min}^{-1}$ velocity to the beginning of permanent deformation. Maximum power $(\mathrm{N})$ needed for the permanent deformation was measured.

\section{Immobilisation and monitoring of antimicrobial effect of nisin}

For these experiments packaging material on starch base with addition of $15 \%$ of sawdust, $5 \%$ of PVOH and $2 \%$ of calcium stearate was chosen. For surface adjustment $30 \%$ Kombilak L1917 and $10 \%$ copolyamide $6 / 12$ with $5 \% \mathrm{w} / \mathrm{w}$ of nisin were used. 
Hydrochloric acid $(1.71 \mathrm{ml}$ of $36 \% \mathrm{HCl})$ and sodium chloride $(7.5 \mathrm{~g})$ were dissolved in $1000 \mathrm{ml}$ of distilled water. In $25 \mathrm{ml}$ of this base solution $0.25 \mathrm{~g}$ of Nisaplin was dissolved and solution with concentration $10000 \mathrm{IU} / \mathrm{ml}$ was prepared. This solution was further diluted to concentrations 1000; 200; $100 ; 50 ; 25$ and $10 \mathrm{IU} / \mathrm{ml}$.

\section{Monitoring of antibacterial effect of nisin released from the packaging}

Above mentioned samples with immobilized nisin were leached in $50 \mathrm{ml}$ of base and stable solution. After 1, 3, 5, 20, 24 and 72 hours $1 \mathrm{ml}$ of leach was taken. Withdrawn solutions were kept in refrigerator.

Sterile MRS agar was mixed with $2 \mathrm{ml}$ of Lactobacillus Helveticus CH1. After spilling into a sterile plate, 36 holes with $0.9 \mathrm{~cm}$ diameter were created. These holes were filled with $170 \mu \mathrm{l}$ of calibration solutions and nisin solutions obtained by leaching from the packaging. Plates were kept in the refrigerator for 24 hours and then they were subsequently transferred for 20 hours in a thermostat with $42{ }^{\circ} \mathrm{C}$ temperature. Inhibition zones produced by nisin diffusion of calibration solutions and from solutions obtained by leaching from the packaging were measured when microorganisms grown.

\section{Monitoring of antibacterial effect of nisin in direct contact with packaging}

Sterile MRS agar was mixed with $2 \mathrm{ml}$ of Lactobacillus Helveticus CH1. Packaging materials were regularly distributed throughout the MRS agar on the plates. Plates were kept in the refrigerator for 24 hours and then they were subsequently transferred for 24 hours in a thermostat with $42^{\circ} \mathrm{C}$ temperature.

\section{Results and Discussion}

The aim of our previous work was to improve the properties of the baked starch form. Starch/water mixture batters with various additives of inorganic and organic compounds were tested. The assumption was that the additions of different components filled in the matrix of the packaging materials and avoid the water infiltration into the structure of the packaging. In this work we have focused our attention to surface adjustment of chosen packaging materials on starch base. For surface adjustment copolyamide 6/12 and Kombilak L1917 were used. Copolyamide was synthesized by direct copolymerization of 6-caprolactam and 12-laurolactam with catalytic effect of phosphoric acid. This process ensures very good properties of the copolymer. Copolyamide 6/12 has a lower proportion of crystalline fraction, consequence of which is solubility in hot ethanol and the ability to soak ingredients and additives in high quantities and to desorbed them by gradual, controlled way.

Kombilak L1917 is a hydrophobic coating for the paint colors used as a carrier for active agents that are tested as preservatives and antimicrobial agents.

In production of packaging materials with bioactive functions it is necessary to immobilize antimicrobial agents into the surface layer of packaging materials. These agents are gradually released from this layer and significantly prolong the shelf life of the packaged food.

Nisin, the active ingredient in the commercial preparation Nisaplin ${ }^{\circledR}$ (antimicrobial agent that is commonly used since 1953 to control bacterial growth in food) is probably the best know and most-recognized bacteriocin. It is effective against a broad spectrum of gram-positive bacteria in the form of vegetative cells and spores. It is a peptide soluble in water, which is the most stable in an acidic environment. Its use is authorized in more than 50 countries (Hanušová et al. 2009).

Based on previous measurements of sorption and mechanical properties starch packaging with additions of calcium stearate, sawdust and polyvinyl alcohol (PVOH) were applied. Chosen samples (Figure 1A) were coated with 15, 20, 25 and $30 \%$ of Kombilak L1917 (Figure 1B) and 5 and $10 \%$ solution of copolyamide 6/12 (Figure 1C).

The results (Figure 2) showed that surface adjustment by coating reduced water vapor sorption. The biggest improvement was achieved by coating with $30 \%$ Kombilak L1917 solution. Copolyamide 6/12 coating improved the properties of prepared packaging materials as well but the results were twice worse than the samples coated by KombilakL1917. The copolyamide $6 / 12$ proved the best results by coating with $10 \%$ solution. Coating by $30 \%$ Kombilak L1917 managed to decrease the sorption of water vapor in 24 hours to the tenth of original value and $10 \%$ of copolyamide $6 / 12$ coating to the fifth of the original value (Figure 2).

Samples coated by 15, 20, 25 and $30 \%$ of Kombilak L1917 and 5 and $10 \%$ of copolyamide 6/12 were exposed to the direct contact with water (Figure 3). Coating with solution of $30 \%$ Kombilak L1917 and $10 \%$ copolyamide 6/12 was sufficient to create a relatively homogeneous polymer layer, which in both cases decreased sensitivity to the water to a minimum value.

Addition of antimicrobial agent, nisin, slightly increased hydrophilicity of samples coated by $30 \%$ of Kombilak L1917 solution and $10 \%$ of copolyamide $6 / 12$ solution. This finding can be explained by disrupted homogeneity of surface coating (caused 

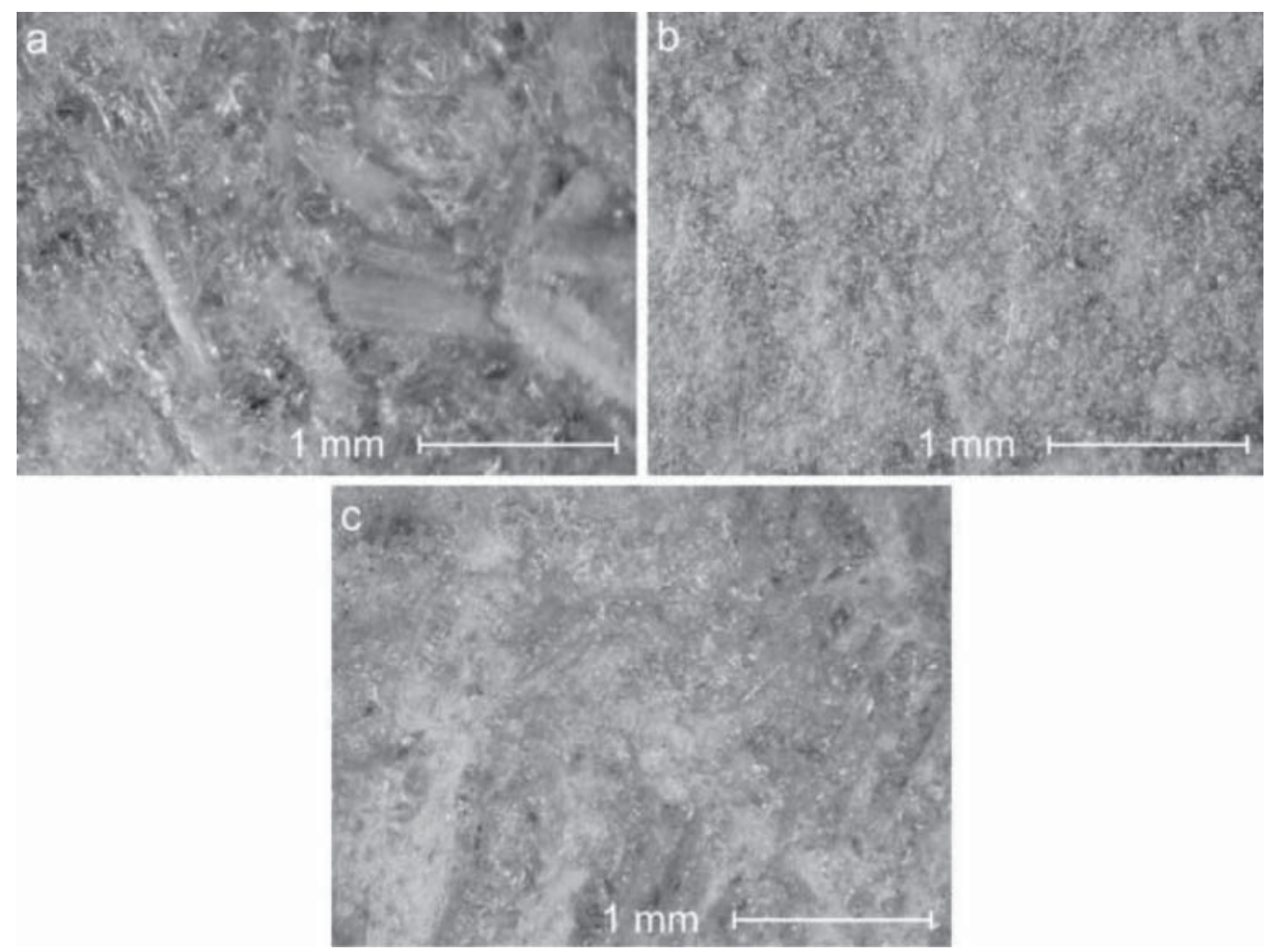

Fig. 1. Surface of tray with

a) addition of $2 \%$ of calcium stearate, $15 \%$ of sawdust and $5 \%$ of $\mathrm{PVOH}$, b) addition of $2 \%$ of calcium stearate, $15 \%$ of sawdust and $5 \%$ of PVOH coated with $30 \%$ solution of Kombilak L1917,

c) addition of $2 \%$ of calcium stearate, $15 \%$ of sawdust and $5 \%$ of PVOH coated with $10 \%$ solution of copolyamide $6 / 12$.

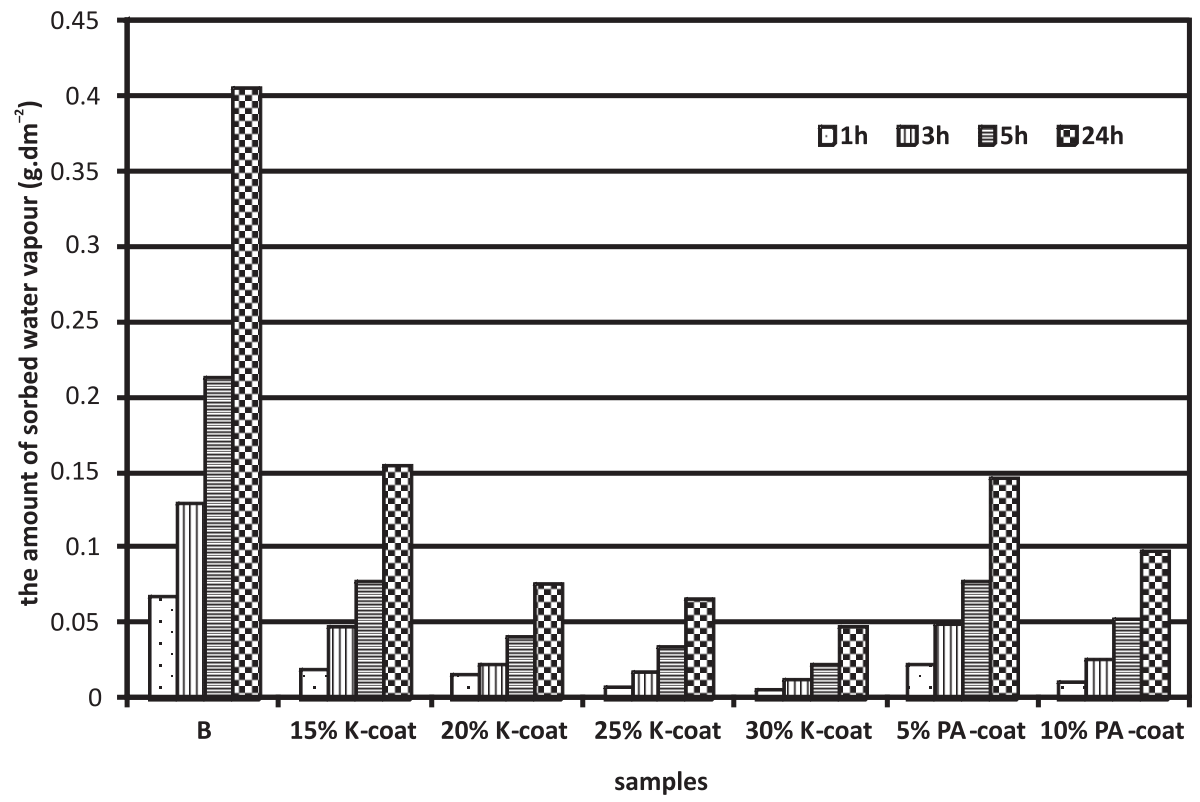

Fig. 2. Measurement of amount of sorbed water vapour onto chosen starch/water trays with additives and adjusted surfaces (for sample specification see Table 1). 


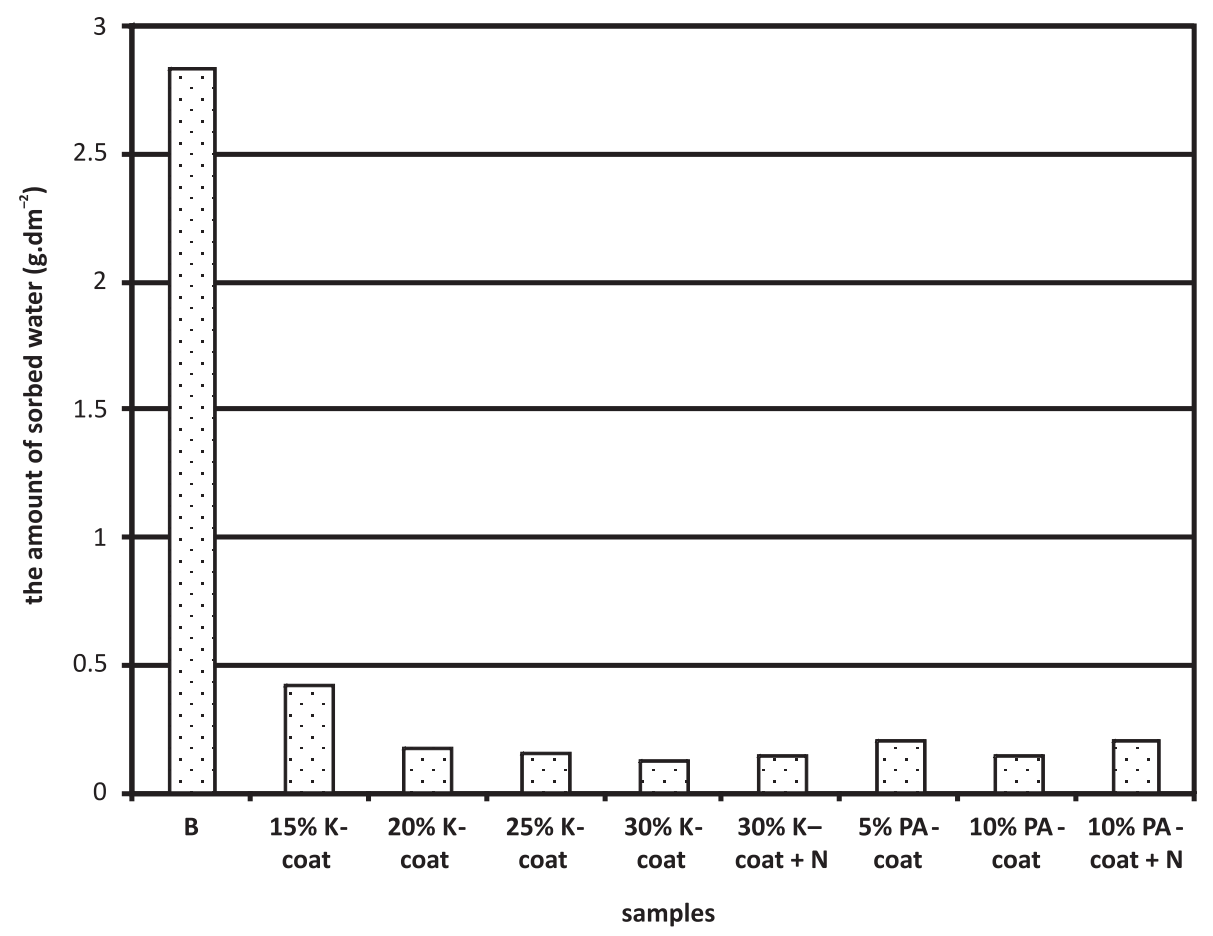

Fig. 3. Measurement of amount of sorbed water to chosen starch/water trays with additives and adjusted surfaces after 1 hour (for sample specification see Table 1).

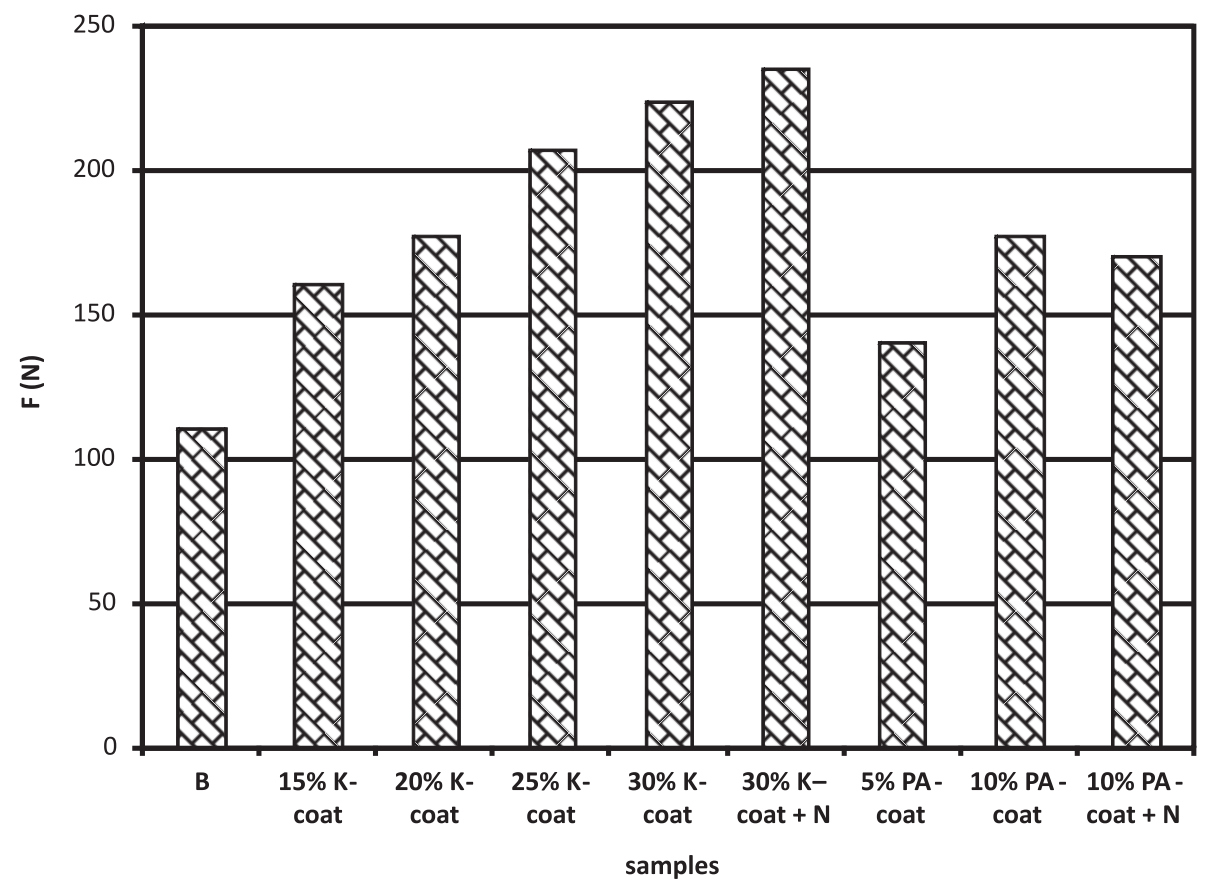

Fig. 4. Measurement of mechanical properties of chosen starch/water trays with additives and adjusted surfaces (for sample specification see Table 1).

by added nisin) which becomes more porous and accessible to the water penetration.

Best mechanical properties were achieved with samples coated with $30 \%$ Kombilak L1917 solution when the power needed for the destruction of the sample increased twice compared with the original sample without coating (Figure 4).
Polyamides are known for their high strength, thanks to which they are used as the outer layer of laminated foil material. This property was confirmed by the results of mechanical resistance of starch base samples. Treatment of surface samples with $10 \%$ copolyamide $6 / 12$ solution resulted in increased mechanical strength by almost $60 \%$ (Figure 4). 
Tab. 1. Specification of samples used in figure 1-3.

\begin{tabular}{|c|c|}
\hline Samples & description of sample \\
\hline B & starch/water mixture with $15 \%$ of sawdust and $2 \%$ of calcium stearate and $10 \%$ of PVOH \\
\hline $15 \%$ K-coat & $\begin{array}{l}\text { starch/water mixture with } 15 \% \text { of sawdust and } 2 \% \text { of calcium stearate and } 10 \% \text { of PVOH coated } \\
\text { with } 15 \% \text { Kombilak L1917 solution }\end{array}$ \\
\hline $20 \%$ K-coat & $\begin{array}{l}\text { starch/water mixture with } 15 \% \text { of sawdust and } 2 \% \text { of calcium stearate and } 10 \% \text { of PVOH coated } \\
\text { with } 20 \% \text { Kombilak L1917 solution }\end{array}$ \\
\hline $25 \%$ K-coat & $\begin{array}{l}\text { starch/water mixture with } 15 \% \text { of sawdust and } 2 \% \text { of calcium stearate and } 10 \% \text { of PVOH coated } \\
\text { with } 25 \% \text { Kombilak L1917 solution }\end{array}$ \\
\hline $30 \%$ K-coat & $\begin{array}{l}\text { starch/water mixture with } 15 \% \text { of sawdust and } 2 \% \text { of calcium stearate and } 10 \% \text { of PVOH coated } \\
\text { with } 30 \% \text { Kombilak L1917 solution }\end{array}$ \\
\hline $30 \%$ K-coat $+\mathrm{N}$ & $\begin{array}{l}\text { starch/water mixture with } 15 \% \text { of sawdust and } 2 \% \text { of calcium stearate and } 10 \% \text { of PVOH coated } \\
\text { with } 30 \% \text { Kombilak L1917 solution with immobilized nisin }\end{array}$ \\
\hline $5 \%$ PA-coat & $\begin{array}{l}\text { starch/water mixture with } 15 \% \text { of sawdust and } 2 \% \text { of calcium stearate and } 10 \% \text { of PVOH coated } \\
\text { in } 5 \% \text { copolyamide } 6 / 12 \text { solution }\end{array}$ \\
\hline $10 \%$ PA-coat & $\begin{array}{l}\text { starch/water mixture with } 15 \% \text { of sawdust and } 2 \% \text { of calcium stearate and } 10 \% \text { of PVOH coated } \\
\text { in } 10 \% \text { copolyamide } 6 / 12 \text { solution }\end{array}$ \\
\hline $10 \%$ PA-coat $+\mathrm{N}$ & $\begin{array}{l}\text { starch/water mixture with } 15 \% \text { of sawdust and } 2 \% \text { of calcium stearate and } 10 \% \text { of PVOH coated } \\
\text { in } 10 \% \text { copolyamide } 6 / 12 \text { solution with immobilized Nisin }\end{array}$ \\
\hline
\end{tabular}

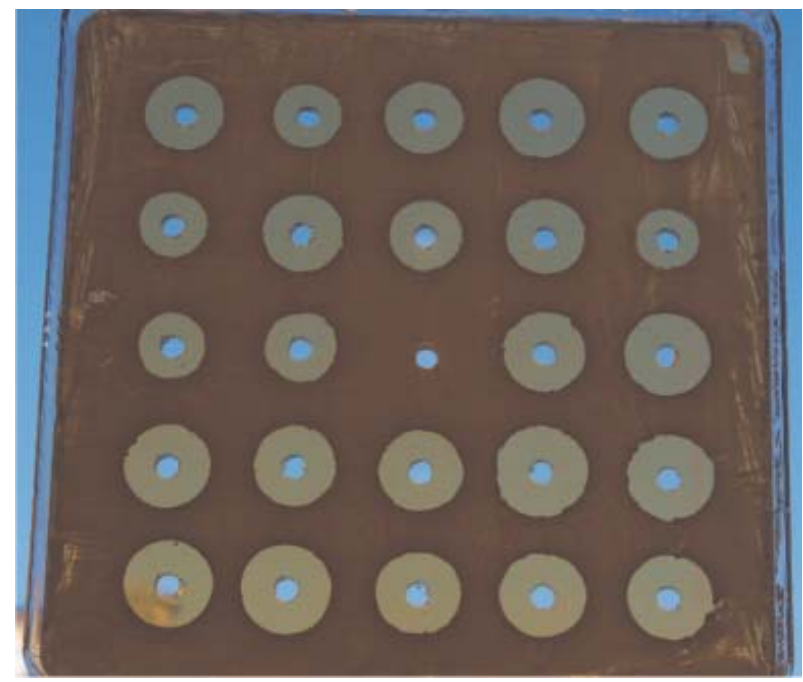

Fig. 5. Antimicrobial activity determination in extracts of bioactive packages.

Immobilization of preservatives had no significant effect on the mechanical strength of coated samples. Antimicrobial activity of modified packaging was verified by measuring zones of inhibition and mutual comparison of bacteriocin released from samples coated with solution of $30 \%$ Kombilak L1917 and $10 \%$ copolyamide $6 / 12$ by means of the agar diffusion test.

The advantage and importance of this method is that the resulting zone extract, obtained from the prepared samples can be immediately compared with the zones of the calibration solutions and quantify the amount of bacteriocin released from the polymer.

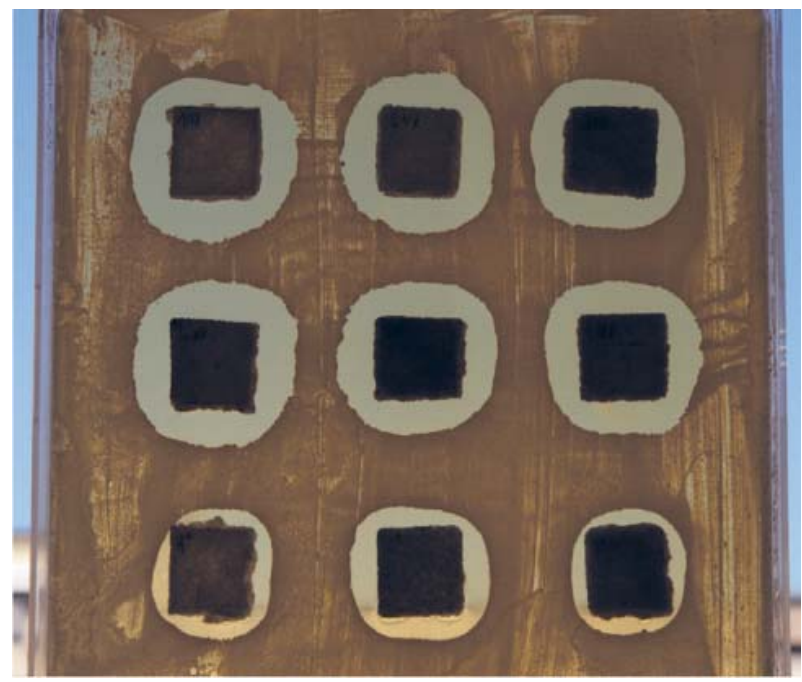

Fig. 6. Antimicrobial activity determination in direct contact with samples of chosen packaging materials with immobilized nisin.

Extracts were collected at intervals of 1, 3, 5, 20, 24 and 72 hours of inserting samples into $0.02 \mathrm{M}$ hydrochloric acid solution, stable for nisin. Measuring the diameter of inhibition zones (Figure 5) and due to equation from calibration graph amount of released nisin was calculated. Sample coated by Kombilak L1917 released almost four times higher amount of nisin. Used amount of immobilized nisin in both types of used polymers was sufficient for effective inhibition of microbial cultures Lactobacillus Helveticus CH1.

Similar results were obtained if prepared bioactive packaging were inserted directly on the plate with microbial culture (see Surface adjustment). Even 
in this case the effective inhibition was evident (Figure 6).

\section{Summary}

Packaging materials on starch base with advanced resistance to water vapour and bigger mechanical stability were prepared thanks to addition of different compounds including reusable materials. Best properties were achieved in the case of packaging material containing $15 \%$ of sawdust, $2 \%$ of calcium stearate and $5 \%$ of polyvinyl alcohol coated with $30 \%$ of Kombilak L1917 solution.

The addition of antimicrobial agent nisin slightly increased hydrophilicity of samples coated by $30 \%$ of Kombilak L1917 solution and $10 \%$ of copolyamide $6 / 12$ solution. The immobilization of preservatives had no significant effect on the mechanical strength of coated samples.

For both types of relevant polymers the concentration of immobilized nisin was quite sufficient for the effective inhibition of microbial cultures Lactobacillus Helveticus $\mathrm{CH} 1$.

\section{References}

Appendini P, Hotchikiss JH (2002) Innovative food Science and Emerging Technologies 3: 113-126.

Cinelli P, Chiellini E, Lawton JW, Imam SH (2006) Polymer Degradation and Stability 5: 1147-1155.

Hanušová K, Dobiáš J (2009) Packaging 2: 42-45.

Marek M, Králová E, Štastníková V, Dobiáš J, Voldřich M (2004) Method of preparation of bioactive packaging materials. International patent WO 2004/056214 A3, International Application Number $\mathrm{PCT} / \mathrm{CZ} 2003 / 000072$.

Regulation (EC) No 1935/2004 of the European Parliament and of the Council of 27 October 2004 on materials and articles intended to come into contact with food and repealing Directives 80/590/EEC and 89/109/EEC.

Shogren RL, Lawton JW, Tiefenbacher KF, Chen L (1998) Journal of Applied Polymer Science 68: 2129-2140.

Shogren RL, Lawton JW, Tiefenbacher KF (2002) Industrial Crops and Products 16: 69-79.

Smítková H, Marek M, Dobiáš J (2012) Czech Journal of Food Science - accepted.

Tiefenbacher K (1993). Journal of Macromolecular Science: Pure and Applied Chemistry A30: 727-731. 